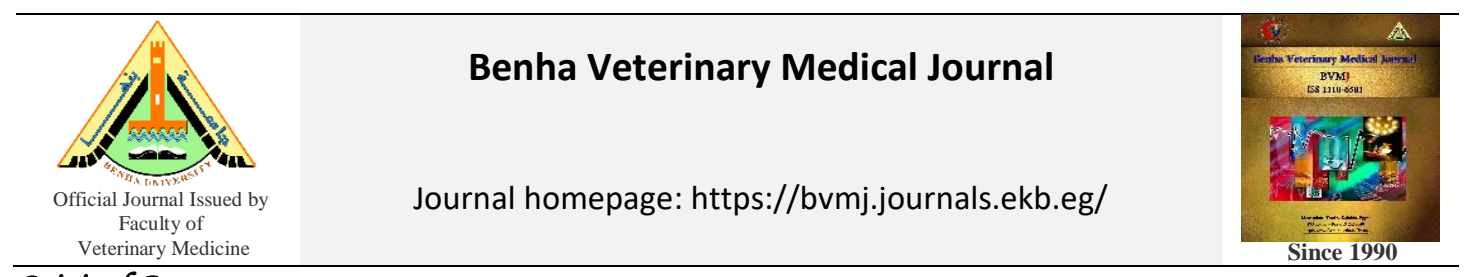

Original Paper

\title{
Zinc nanoparticles coated with Gallic acid potentially ameliorate hepatocellular carcinoma-induced in rats
}

Shoker, Faten Elkenany ${ }^{1}$, AbouZaid, Omayma Ragab ${ }^{1}$, EL-sonbaty, Sawsan Mohammed ${ }^{2}$

${ }^{1}$ Department of Biochemistry, Faculty of Veterinary Medicine, Moshtohor, Benha University.

${ }^{2}$ Radiation Microbiology Department, National Centre for Radiation Research and Technology. Egypt.

\begin{tabular}{|c|c|}
\hline ARTICLE INFO & ABSTRACT \\
\hline $\begin{array}{l}\text { Keywords } \\
\text { Cytotoxicity } \\
\text { HCC } \\
\text { HepG2 cell line } \\
\text { Liver function tests } \\
\text { Zn-GANPs } \\
\text { Received 24/09/2019 } \\
\text { Accepted 08/11/2019 } \\
\text { Available On-Line } \\
\text { 12/05/2020 }\end{array}$ & $\begin{array}{l}\text { Materials on the nanoscale are increasingly being targeted to cancer cells with great specificity } \\
\text { through both active and passive targeting. In the current study, the potential therapeutic effect } \\
\text { of the newly synthesized Zinc nanoparticles coated with Gallic acid (Zn-GANPs) against } \\
\text { hepatocellular carcinoma (HCC) - induced in rats were evaluated. Forty rats were divided into } \\
\text { four equal groups, group } 1 \text { : normal control, group } 2 \text { : received diethylnitrosamine (DEN) (20 } \\
\text { mg/Kg b.wt, } 5 \text { times per week for } 8 \text { weeks), group } 3 \text { : received Zn-GANPs ( } 20 \mathrm{mg} / \mathrm{kg} \text { b. wt./day, } \\
\text { i.p) from the onset of the } 9 \text { th week till the end of the experiment (13 weeks), group 4: DEN + } \\
\text { Zn-GANPs treated group: Rats were received DEN as group (2) and subsequently treated with } \\
\text { Zn-GANPs as group (3) till the end of the experiment (13 weeks).Blood samples and liver } \\
\text { tissue specimens were collected for biochemical analysis and histopathological examination. } \\
\text { The obtained results revealed that in HCC-induced rats serum aspartate aminotransferase } \\
\text { (AST) activity, total bilirubin and creatinine levels were increased, while total protein, albumin } \\
\text { concentrations and liver catalase activity were significantly decreased as compared with control } \\
\text { normal group. Administration of Zn-GANPs to HCC-induced rats non-significantly reduced } \\
\text { serum AST activity, total bilirubin and creatinine concentrations. However, serum total protein } \\
\text { and albumin levels were non-significantly increase and liver catalase activity was markedly } \\
\text { increased in Zn-GANPs treated liver cancer group. Ameliorative effect of Zn-GANPs was } \\
\text { appreciated with the histopathological alterations observed in DEN groups. These results } \\
\text { suggesting the efficacy of Zn-GaNPs administration as an anti-HCC }\end{array}$ \\
\hline
\end{tabular}

\section{INTRODUCTION}

Hepatocellular carcinoma (HCC) develops in the liver hepatocytes and considered as the fifth most common malignancy and second most common cause of cancer death. More than 700,000 people are diagnosed with HCC and 600,000 deaths are reported internationally each year. HCC accounts for $82 \%$ of all liver cancers diagnosed (Ferlay et al., 2015)

Indeed, it is known that hepatocarcinogenesis result from the combination of several causes, such as genetic, immunological, virus-related, environmental and host factors include heavy alcohol abuse, cigarette smoking, and exposure to aflatoxin. Host-related factors include male gender, age of at least 50 years, family predisposition, obesity, advanced liver fibrosis or cirrhosis and co-infection with other hepatotropic viruses and human immunodeficiency virus (Ružić et al., 2018) .

In Egypt, HCC is the fourth most common cancer and is the second cause of cancer mortality in both sexes. In the last decades, a twofold increase of HCC was reported among chronic liver disease patients in Egypt with a significant decline of hepatitis B virus (HBV) and slight increase of hepatitis $\mathrm{C}$ virus ( $\mathrm{HCV}$ ) as risk factors. $\mathrm{HCV}$ is an important risk factor for $\mathrm{HCC}$ in Egypt where $71 \%$ of $\mathrm{HCC}$ cases were positive for anti-HCV antibodies (Yapali and Tosun, 2018). The importance of micronutrients in health and nutrition is undisputable, and among them, zinc is an essential element whose significance to health is increasingly appreciated and whose deficiency may play an important role in the appearance of diseases. Zinc is one of the most important trace elements in the organism, with three major biological roles, as catalyst, structural, and regulatory ion. Also, zincbinding motifs are found in many proteins encoded by the human genome physiologically, and free zinc is mainly regulated at the single-cell level. Moreover, zinc has critical effect in homeostasis, in immune function, in oxidative stress, in apoptosis, and in aging. In many chronic diseases, including atherosclerosis, several malignancies, neurological disorders, autoimmune diseases, aging, agerelated degenerative diseases, cancer, diabetes, depression, Wilson's disease and Alzheimer's disease (Chasapis et al., 2012). Also, beneficial therapeutic responses of zinc

\footnotetext{
* Corresponding author: Prof. AbouZaid, Omayma Ragab. Department of Biochemistry, Faculty of Veterinary

Medicine, Moshtohor, Benha University.
} 
supplementation have been observed in acute diarrhea in children, chronic hepatitis C, shigellosis, leprosy, leishmaniasis, and common cold. Zinc supplementation was effective in decreasing incidences of infection in elderly and patients with sickle cell disease. Zinc supplementation was effective in preventing blindness in $25 \%$ of the elderly with dry type of age-related macular degeneration. Zinc supplementation in the elderly decreased oxidative stress and decreased generation of inflammatory cytokines. Zinc is an intracellular signaling molecule in monocytes, dendritic cells and macrophages and it plays an important role in cellmediated immune functions and oxidative stress. Zinc is also an anti-inflammatory agent. These unique properties of zinc may have significant therapeutic benefits in several diseases in humans the concurrent zinc deficiency may complicate the clinical features, affect adversely immunological status, increase oxidative stress, and lead to the generation of inflammatory cytokines. In these diseases, oxidative stress and chronic inflammation may play important causative roles(Prasad, 2009). Additionally, zinc is known as an antioxidant agent that contributes in the stabilization of cellular membrane and cytoskeleton, as an anti-apoptotic agent and as a co-factor in Deoxy-Ribonucleic Acid (DNA) synthesis (Truong-Tran et al., 2000). As well as The treatment of HepG2 cells with physiological concentrations of zinc under conditions that result in the cellular uptake and accumulation of zinc results in inhibition of cell proliferation (Franklin et al., 2012).

Oxidative stress, a result of an overproduction and accumulation of free radicals, is the leading cause of several degenerative diseases such as cancer, atherosclerosis, cardiovascular diseases, ageing and inflammatory diseases. Polyphenols form an important class of naturally occurring antioxidants, having innumerable biological activities such as anticancer, antifungal, antibacterial, antiviral, antiulcer and anticholesterol, to name a few. Among various polyphenols, Gallic acid (3, 4, 5-trihydroxybenzoic acid), a naturally occurring low molecular weight triphenolic compound, has emerged as a strong antioxidant and an efficient apoptosis inducing agent. Gallic acid derivatives have also been found in a number of phytomedicines with diverse biological and pharmacological activities, including radical scavenging, interfering with the cell signaling pathways and apoptosis of cancer cells. The diverse range of applications of this simple polyphenol is due to a fine amalgam between its antioxidant and prooxidant potential (Badhani et al., 2015)

Gallic acid (GA) has inhibitory effects on cancer cell growth at different molecular levels either in chemicalinduced carcinogenic models or in vitro cancerous cell lines. GA selectively inhibits cancer cell growth via the modulation of genes that encodes for cell cycle, metastasis, apoptosis and angiogenesis with little or almost no toxicity upon normal cells. However, a major obstacle that limits the clinical use of GA is its low bioavailability (Ahmed et al., 2018).

The hepatocarcinogenic effect of $\mathrm{N}$-nitrosodiethylamine can be abrogated by gallic acid supplementation owing to its affinity to regulate signal transducer and activator of transcription 3 signaling pathway through its outstanding bioactivities including antioxidant, anti-inflammatory, apoptotic, and antitumor effects (Aglan et al., 2017).

Most HCCs are diagnosed at advanced stages, treatment options for HCC are limited (Bruix and Sherman, 2011) .
Therefore, there is an unmet clinical need for development of novel effective treatments for HCC. Nanoparticles have been used in medicine to deliver drugs targeting to certain tissues and to increase stability against degradation by enzymes.

Nanotechnology is defined as the introduction, manipulation, and use of materials on the nanometer size scale $(1-100 \mathrm{~nm})$. Even though nanoscale materials may be made by the use of variable traditional physical and chemical techniques, it's presently feasible to biologically synthesize substances through surroundings pleasant green chemistrybased techniques. Nanoparticles are of chemical, biological and physical differences in their properties compared to the bulk of the same chemical constituents (Daniel and Astruc, 2004).

The advent of nanocarriers for drug delivery has given rise to new intriguing scenarios in the cancer field. Nanocarriers indeed partly overcome the limits of traditional cytotoxic drugs principally changing the pharmacokinetic behavior of the parental drug. The peculiar characteristics of these systems strongly minimize the adverse reactions and ensure a more precise release of the compound to the tumor site (Giodini et al., 2017). Accordingly, evaluation of anticancer potential of zinc nanoparticles coated by gallic acid ( $\mathrm{Zn}$ GANPs), a novel nanocomposite, against DEN induced hepatocellular carcinoma in rats as a novel approach in the field of cancer biology were investigated.

\section{MATERIAL AND METHODS}

\subsection{Chemicals:}

- Diethylnitrosamine (DEN) was obtained from Sigma Chemical Co. (St.Louis, MO, USA) and purchased from Schnelldorf, Germany through the Egyptian International Center for Import Cairo, Egypt

- Zinc chloride: $\mathrm{ZnCl}_{2}$, anhydrous, $98+\%$ was purchased from Alfa Aesar

- Gallic acid: 3,4,5-Trihydroxybenzoic acid was purchased from Oxford Lab Chem.

- All the aqueous solutions of zinc nanoparticles coated by gallic acid (Zn-GaNPs) were prepared using distilled water

\subsection{Biosynthesis of ZnNPs coated by GA (Zn-GANPs):}

Zinc nanoparticles (ZnNPs) were synthesized according to the method of (Moreno-Álvarez et al., 2010). Briefly, $2.0 \mathrm{ml}$ of $\left(\mathrm{ZnCl}_{2}\right)(20 \mathrm{mM})$ was added to $46.0 \mathrm{ml}$ of double- distilled water under magnetic stirring at room temperature. Then 2.0 $\mathrm{ml}$ of GA $(10 \mathrm{mM})$ was added, and the $\mathrm{pH}$ value was adjusted to 11.0 with $1.0 \mathrm{M} \mathrm{NaOH}$. Then the reaction was maintained at room temperature for $30 \mathrm{~min}$. the nanoparticles was condensed and purified by centrifugation at 15000 r.p.m for $10 \mathrm{~min}$. and washed by double- distilled water three times.

\subsection{Cytotoxicity test (In vitro)}

The antitumor effect of Zn-GANPs represented by $50 \%$ inhibitory concentration $\left(\mathrm{IC}_{50}\right)$ was investigated on the viability of the hepatocellular carcinoma cell line (HepG2) using the MTT assay (Berridge et al., 2005).

Human hepatocellular liver carcinoma cell lines HepG2 was obtained from Egyptian National Cancer Institute, Cairo University and these cells were cultured in DMEM (Biowest, France) supplemented with $10 \%(\mathrm{v} / \mathrm{v})$ fetal 
bovine serum (FBS were acquired from Hyclone Lab Inc ) and $1 \%$ antibiotic solution, respectively. To determine the cell viability, healthy viable cells were seeded to $100 \mu \mathrm{L}$ cell culture plates $\left(3 \times 10^{3}\right.$ cell/well $)$ After incubation (overnight), the nano compound was added in various concentrations $(0.1-32 \mathrm{mg} / \mathrm{ml})$, After treatment with $\mathrm{Zn}$ GaNPs for one day, $20 \mu \mathrm{lof} 5 \mathrm{mg} / \mathrm{ml} \mathrm{MTT} \mathrm{(pH} \mathrm{4.7)} \mathrm{was}$ added per well and incubated for another $4 \mathrm{~h}$, The supernatant fluid was removed and $100 \mu \mathrm{l}$ of $(0.1 \%$ dimethyl sulfoxide (DMSO)) was added per well and shaken for $15 \mathrm{~min}$. The absorbance at $570 \mathrm{~nm}$ was measured with a microplate reader (Bio-Rad, Richmond, $\mathrm{CA})$. The cell viability percentage was determined according to the kit protocol, and cell viability percentage was plotted on a graph.

\subsection{LD50 Value (In vivo)}

$\mathrm{Zn}-\mathrm{GaNPs}$ was used throughout the experiment. This method involves the administration of different doses of $\mathrm{Zn}$ GaNPs i.e., 1, 10, 30, 100, 300 and $500 \mathrm{mg} / \mathrm{kg}$ body weight were administered intraperitoneal to various groups, which had five animals each. The first group of animals is administered with the vehicle in which the test substance was dissolved or diluted in water. However, from the second group onward receives different doses of the test substance. The animals in each group receives specific doses, while increment in dose progresses from group to group (starting from group 2 which receives the lowest dose). The interval mean of a number of mortalities recorded in each group and dose difference across the groups are key parameters in this method (Turner, 2013). The LD50 is calculated using the arithmetical method of Karber.

\subsection{Experimental animals:}

Forty male albino rats (100-120 g) aged about 4 weeks were used in this study. Animals were obtained from Animal House Colony of the National Research Centre, Giza, Egypt. Animals were housed in cages and maintained under standard conditions of ventilation, temperature and humidity. Animals received standard food pellets and water ad libitum. All animal treatment procedures conformed to the National Institutes of Health (NIH) guidelines.

\subsection{Preparation and administration of dosage:}

Hepatocellular carcinoma was induced by administration of DEN (20mg/kg b.wt/day) dissolved in 0.9 saline orally five time per week for six weeks according to Darwish and ELboghdady (2013) and two more weeks for effective induction.

Based on Gallic acid at dose of $20 \mathrm{mg} / \mathrm{kg}$, i.p. showed antioxidant activity (Chhillar and Dhingra, 2013). Also, toxicity study for $\mathrm{Zn}$-GaNPs , no mortality occurred during experimental period, So, Zn-GaNP can be intraperitoneal injected at a dose range of $20 \mathrm{mg} / \mathrm{kg}$ and without any side effects from the ninth week till the end of the experiment (13 weeks).

\subsection{Experimental design:}

Rats were randomly divided into four equal groups, 10 animals each, and were classified as follow:

- Group (1): Normal control group: Rats received normal saline, served as untreated control.

- Group (2): DEN group: received DEN (20 mg/Kg b. wt, 5 times per week for 8 weeks)
- Group (3): Zn-GANPs: Rats received Zn-GANPs (20 $\mathrm{mg} / \mathrm{kg} \mathrm{b}$. wt/day, i.p) from the onset of the 9th week till the end of the experiment (13 weeks).

- Group (4): DEN + Zn-GANPs treated group: Rats received DEN as group (2) and subsequently treated with Zn-GANPs as group (3) till the end of the experiment (13 weeks).

\subsection{Sampling}

2.8.1. Blood samples:

Blood samples were collected by heart puncture in dry, clean test tubes and allowed to clot for $30 \mathrm{~min}$ and serum was separated by centrifugation at $3000 \mathrm{rpm}$ for $15 \mathrm{~min}$. The serum was separated by automatic pipette and received in dry sterile tubes, processed directly for Serum aspartate aminotransferase (AST), total protein (T.P), albumin (ALB), total bilirubin (T.BILI) and creatinine (CREAT) which were determined according to the method described by (Bergmeyer et al., 1986; Henry, 1964; Doumas et al., 1971; Jendrassik and Grof, 1938; Murray, 1984, respectively). After blood samples collection rats were decapitated to collect liver samples.

\subsubsection{Tissue specimens (liver):}

\subsubsection{For biochemical analysis:}

Liver tissues were collected from all rat groups put in Eppendorf tubes and immediately stored at $-20^{\circ} \mathrm{C}$ for determination of Catalase (CAT).

Liver samples for preparation of tissue homogenates were divided into appropriate portions, homogenized with a glass homogenizer in 9 volume of ice-cold $0.05 \mathrm{mM}$ potassium phosphate buffer ( $\mathrm{pH} 7.4)$ to make $10 \%$ homogenates. The homogenates were centrifuged at 6000 $\mathrm{rpm}$ for 15 minutes at $4{ }^{\circ} \mathrm{C}$ and the resultant supernatant was used for the determination of CAT-according to the method described by (Aebi, 1984)

\subsubsection{For Histopathological examination:}

Liver tissue specimens were taken from different parts of the liver of male rats and preserved in $10 \%$ buffered neutral formalin, dehydrated, fixed in paraffin wax blocks and subjected to microscopic examination according to Banchroft et al. (1996).

\subsection{Statistical analysis}

Data were represented as (Mean \pm S.E). Statistical analysis of data was carried out using one-way ANOVA under significance level of $0.05(\mathrm{P} \leq 0.05)$ using GraphPad Prism 7 software (Swift, 1997)

\section{RESULTS}

Results of Zn-GANPs cytotoxicity on liver cancer cell line HepG2 is shown in fig 1. Zn-GANPs exhibited a cytotoxic effect against human hepatocellular carcinoma cell line (HepG2), which recorded $\mathrm{IC}_{50}$ value $(0.7 \mathrm{mg} / \mathrm{mL})$.

A significant increase was recorded in serum aspartate aminotransferase (AST) activity, total bilirubin (T.BILI) levels and in serum creatinine (CREAT) concentration however a significant decrease in serum total protein (T.P) and albumin (ALB) concentration as well as liver tissue CAT activity. 


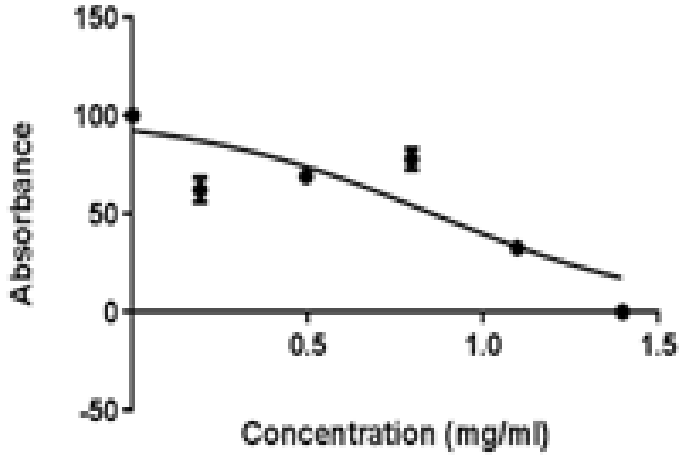

Fig 1 Cytotoxicity of IC50 of Zn-GaNPs against HepG2 cell line

Intraperitoneal injection with $\mathrm{Zn}-\mathrm{GaNPs}$ to control rats resulted in a significant decrease in Serum AST activity, T.BILI levels and CREAT concentration and a significant increase in T.P, ALB concentration and CAT activity when

\section{A}

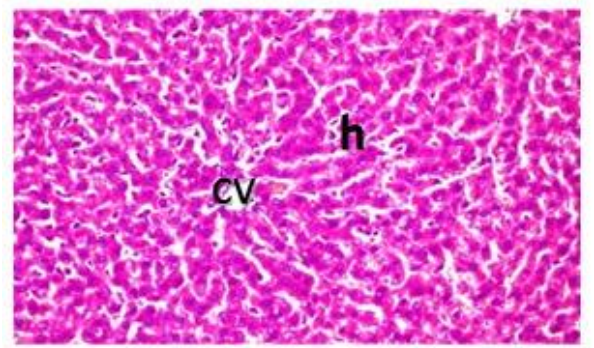

$\mathrm{C}$

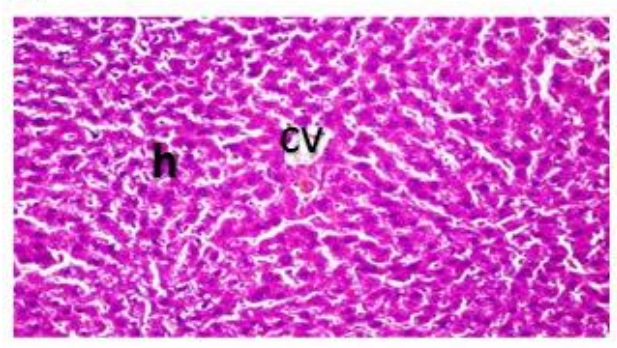

compared with control normal group. Treatment with $\mathrm{Zn}$ GaNPs to DEN rats ameliorate the levels of different parameters when compared with control DEN non-treated group.

Histopathological examination of liver tissue (a): a photomicrograph of the liver tissue with the normal histological structure of the central vein and surrounding hepatocytes in the parenchyma, (b): a photomicrograph of the liver tissue treated with DEN, which represents strands of fibroblastic cells proliferation was dividing the vacuolar degenerated and coagulative necrosis hepatocytes into lobules (c): a photomicrograph of the liver tissue treated with Zn-GANPs showing normal histological structure (d): histological section of the liver cancer tissue in rats treated with Zn-GANPs represents improvement in liver tissues morphology by showing vacuolar degeneration as well as fatty change in diffuse manner all over the hepatocytes in the parenchyma with very few strands of fibrous tissue, (Fig 2), respectively.

$\mathbf{B}$

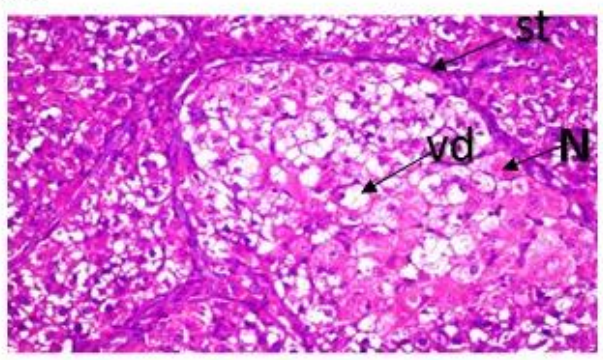

D

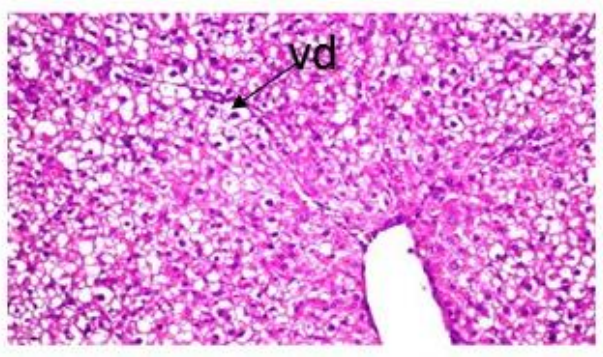

Fig 2 Histopathological examination of liver tissue A: control group, showing normal histological structure of the central vein (cv) and surrounding hepatocytes (h). B: DEN treated group showing vacuolar degenerated (vd) hepatocytes and the coagulative necrosis $(\mathrm{N})$ of hepatocytes with strands of fibrous tissue (st); C: liver tissue of rats treated with Zn-Ga NPs represents normal histological structure. D: liver cancer tissue treated with with $\mathrm{Zn}$-Ga NPs showing the diffuse vacuolar degeneration (VD) in hepatocytes all over the parenchyma. All slides were stained with H\&E and were photographed at $\mathrm{x} 40$

\section{DISCUSSION}

Gallic acid (GA) is a naturally available polyphenol, possess strong antioxidant activity with a capacity to inhibit the formation of tumors in several cancer models. also gallic acid is a potent antiproliferative agent against DENinduced HCC.(Jagan et al., 2008; Aglan et al., 2017), whereas zinc treatment of HepG2 cells exhibited cytotoxic effects that involved the inhibition of mitochondrial maconitase activity; which is a specific direct effect of zinc accumulation in mammalian cells (Lemire et al., 2008). The toxicity test (Fig. 1) with hepatocellular carcinoma cell lines revealed the novel nanocomposite (Zn-GaNPs ) has antitumor effect and inhibitory concentration 50 (IC 50 ) as expected due to its previously demonstrated ability of zinc and gallic acid.

In the current work, we evaluate the therapeutic efficacy of newly synthesized $\mathrm{Zn}$-GANPs in both in vitro and in vivo against DEN-induced hepatocellular carcinogenesis. Several classes of chemicals promote HCC in rodents, including DEN, DEN, one of the most important environmental carcinogen, has been suggested to cause the generation of reactive oxygen species (ROS) resulting in oxidative stress and cellular injury(Bartsch et al., 1989) . As liver is the main site of DEN metabolism, the production of ROS in liver may be responsible for its carcinogenic effects (Bansal et al., 2005). DEN has been appeared to be processed by cytochrome P-450 (CYP 2E1) to its dynamic ethyl radical metabolite, which interacts with DNA causing change and carcinogenesis (Anis et al., 2001)

AST and ALT are reliable marker enzymes of liver and they are the first enzymes to be used in diagnostic enzymology when liver damage has occurred (Whitby et al., 1984). Becauseof their intracellular location in the cytosol, toxicity affecting the liver with subsequent breakdown in mem-brane architecture of the cells leads 
to their spillage into serum, and their concentration rises in the latter.

DEN intoxication showed a significant increase in serum transaminases activities due to over production of these enzymes in tumor cells, which might have caused increase in the permeability of cell membrane resulting in liberation of this enzyme into serum (Ramakrishnan et al., 2007; AlRejaie et al., 2009; Claimer et al., 2012)

$\mathrm{Zn}$-GaNPs treatment significantly attenuated the increased activities of these enzymes which might be due to the ability of GA to uphold parenchymal cell regeneration in liver, thus protecting membrane integrity, thereby decreasing enzyme leakage (Jadon et al., 2007; Jagan et al., 2008). Also, improvement of liver injury in zinc administration is caused by normalization of both extracellular ATP clearance and adenosine generation (Takeda et al., 2018), and treatment with $\mathrm{Zn}$ reduced the increased AST (Yoshioka et al., 2016). Serum bilirubin is one of the most sensitive tests employed in the diagnosis of hepatic diseases. It provides useful information on how well the liver is functioning (Harper, 1961). A significant increase in the level of serum bilirubin was observed in DEN administered rats, which may be a result of mass inhibition of the conjugation reaction and release of unconjugated bilirubin from damaged hepatocytes (Rajkapoor et al., 2006; Barbisan et al., 2003). Similar results were reported in many studies such (Abe et al., 2012). Also, this elevation may be due to decreased conjugation and decreased secretion from the liver or blockage of bile ducts (Bun et al., 2006)

Decrease in serum bilirubin after treatment with Zn-GaNPs indicated the effectiveness of the drug in the maintaining the normal functional status of the liver. The effect of Zn-GANPs on serum bilirubin may be due to the role of gallic acid and $\mathrm{Zn}$ in stabilizing the cell membrane and protect the liver from free radical-mediated liver cell (Tupe et al., 2010; Lee, 2018; Akbari et al., 2019). This suggestion was confirmed by the histopathological findings in $\mathrm{Zn}$ GANPs treated group that show some improvement of the hepatocellular architecture with more regular and less altered hepatocytes.

The total protein test measures the total amount of two classes of proteins found in the fluid portion of the blood. These are albumin and globulin. HCC development is associated with low serum total protein level (Abbasi et al., 2012). In case of DEN-induced HCC, Studies have shown that cellular proteins may be affected by free radical accumulation leading to the formation of carbonyl derivatives. The carbonyl derivatives of proteins may result from oxidative modification of amino acid side chains and reactive oxygen-mediated peptide cleavage (Stadtman and Levine, 2003). Moreover, These free radicals are capable of damaging biological molecules such as proteins that have an impact on cell activities as well as membrane functions and structure. In the present study, treatment with $\mathrm{Zn}$-GaNPs in liver cancer induced rats exhibited a significant increase in serum total protein and albumin concentrations when compared with the DEN group.

The mode of action of $\mathrm{Zn}$-GANPs can be intercepted pharmacologically at different levels with agents that scavenge free reactive oxygen, block their generation, or enhance endogenous antioxidant capabilities of zinc (Tupe et al., 2010) and Gallic acid was also identified as a versatile scavenger, capable of rapidly deactivating a wide variety of reactive oxygen species (ROS) and reactive nitrogen species
(RNS) via electron transfer at physiological $\mathrm{pH}$ (Marino et al., 2014).

The present study showed that the administration of DEN induced renal damage and this was evident by the increased levels of serum toxicity markers like creatinine of DEN-induced rats. It has been reported that serum creatinine level relates to glomerular function and its rise is an indicator of renal failure(Adeneye and Benebo, 2008). These findings are in agreement with the studies of (Rezaie et al., 2013; Shaheen, 2014; Pashmforoosh et al., 2015; Shahin et al., 2018), who demonstrated increased serum urea and creatinine levels in DEN-administered rats.

Zn-GANPs markedly reduced the levels of serum urea and creatinine exhibiting effective improvement of kidney function of HCC induced rats.

Catalase (CAT) is a well-studied enzyme that plays an important role in protecting cells against the toxic effects of hydrogen peroxide. In human, it has been implicated in different physiological and pathological conditions. Numerous studies have described the CAT polymorphisms and their link with various diseases. Changes in the CAT levels were reported in many different diseases and polymorphisms in the CAT gene were shown to be associated with different pathophysiological states, e.g. hypertension, diabetes mellitus, insulin resistance, dyslipidemia, asthma, bone metabolism or vitiligo (Kodydková et al., 2014). CAT is an important enzymic antioxidants that act against toxic oxygen free radicals such as superoxide $(\mathrm{O}-\cdot 2)$ and hydroxyl ions $(\cdot \mathrm{OH})$ in biological systems (Burton et al., 1983). CAT prevents oxidative hazards by catalyzing the formation of $\mathrm{H}_{2} \mathrm{O}$ and $\mathrm{O}_{2}$ from $\mathrm{H}_{2} \mathrm{O}_{2}$ (Rajeshkumar and Kuttan, 2003).

Data from this study revealed that DEN significantly decreased CAT in liver tissues, suggesting that reactive oxygen and nitrogen species induced by DEN play an important role in DEN-induced hepatic carcinogenesis. Increased generation of ROS and decreased antioxidant enzymes in liver tissues has been reported in many models of DEN-induced hepatocellular carcinoma (Yadav and Bhatnagar, 2007; Sivaramakrishnan et al., 2008; Al-Rejaie et al., 2009)

Treatment with Zn-GANPs in rats induced liver cancer exhibited a significant increase in CAT activity. GA administration significantly normalized the reduced CAT activity. This may be due to the free radical scavenging and antioxidant property (Son and Lewis, 2002) of GA which is supposed to be achieved by its trapping $\mathrm{O} 2$ to form stable radicals of itself (Hatano et al., 1989). Also, Zn treatment resulted in an elevation in the levels catalase according to (Goel et al., 2005). The protective effect of zinc on CAT activity may be owed to antiperoxidative property of this metal ion, which in turn leads to decrease in production of superoxide radicals (Swelam et al., 2017). Zinc has also a role as co-enzyme of SOD and it may have antioxidant properties (Powell, 2000).

\section{CONCULOSION}

From the obtained results it could be concluded that, ZnGANPs have anti-proliferative and apoptotic effects in HepG2 cells and have serum biochemical parameters improvement of DEN-induced HCC in rats, which confirmed by histological results. Thus, the newly 
synthesized compound Zn-GANPs can serve as a good therapeutic agent for the treatment of HCC.

\section{REFERENCES}

1. Abbasi, A., Bhutto, A. R., Butt, N. \& Munir, S. M. (2012). Corelation of serum alpha fetoprotein and tumor size in hepatocellular carcinoma. JPMA-Journal of the Pakistan Medical Association 62(1): 33.

2. Abe, R., Okano, J.-I., Imamoto, R., Fujise, Y. \& Murawaki, Y. (2012). Sequential analysis of diethylnitrosamine-induced hepatocarcinogenesis in rats. Experimental and therapeutic medicine 3(3): 371-378.

3. Adeneye, A. A. \& Benebo, A. S. (2008). Protective effect of the aqueous leaf and seed extract of Phyllanthus amarus on gentamicin and acetaminophen-induced nephrotoxic rats. Journal of ethnopharmacology 118(2): 318-323.

4. Aebi, H. (1984). Catalase in vitro. In Methods in enzymology, $105,121-126$.

5. Aglan, H. A., Ahmed, H. H., El-Toumy, S. A \& .Mahmoud, N. S. (2017). Gallic acid against hepatocellular carcinoma: An integrated scheme of the potential mechanisms of action from in vivo study. Tumor Biology 39(6): 1010428317699127.

6. Ahmed, H. H., Galal, A. F., Shalby, A. B., Abd-Rabou, A. A \& Mehaya ,F. M. (2018). Improving anti-cancer potentiality and bioavailability of gallic acid by designing polymeric nanocomposite formulation. Asian Pacific journal of cancer prevention: APJCP 19(11): 31-37.

7. Akbari, G., Savari, F., Mard, S. A., Rezaie, A. \& Moradi, M. (2019). Gallic acid protects the liver in rats against injuries induced by transient ischemia-reperfusion through regulating microRNAs expressions. Iranian journal of basic medical sciences 22(4): 439

8. Al-Rejaie, S. S., Aleisa, A. M., Al-Yahya, A. A ,.Bakheet, S A., Alsheikh, A., Fatani, A. G., Al-Shabanah, O. A. \& SayedAhmed, M. M. (2009). Progression of diethylnitrosamineinduced hepatic carcinogenesis in carnitine-depleted rats. World journal of gastroenterology: WJG 15(11): 1373

9. Anis, K., Rajeshkumar, N. \& Kuttan, R. (2001). Inhibition of chemical carcinogenesis by berberine in rats and mice. Journal of Pharmacy and Pharmacology 53(5): 763-768.

10. Badhani, B., Sharma, N. \& Kakkar, R. (2015). Gallic acid: a versatile antioxidant with promising therapeutic and industrial applications. Rsc Advances 5(35): 27540-27557.

11. Banchroft, J., Stevens, A. \& Turner, D. (1996). Theory and practice of histological techniques. Churchil Livingstone, New York, London, San Francisco, Tokyo: 129-134.

12. Barbisan, L. F ,.Scolastici, C., Miyamoto, M., Salvadori, F., Maria, D., Ribeiro, L. R., Da Eira, F. \& Viana de Camargo, J. L. (2003). Effects of crude extracts of Agaricus blazei on DNA damage and on rat liver carcinogenesis induced by diethylnitrosamine. Genetics and Molecular Research: 295308.

13. Bartsch, H., Hietanen, E. \& Malaveille, C. (1989) Carcinogenic nitrosamines: free radical aspects of their action. Free radical Biology and medicine 7(6): 637-644.

14. Bergmeyer, H., Herder, M. \& Ref, R. (1986). International Federation of Clinical Chemistry (IFCC). J. Clin. Chem. Clin. Biochem 24(7): 497-510.

15. Berridge, M. V., Herst, P. M. \& Tan, A. S. (2005). Tetrazolium dyes as tools in cell biology: new insights into their cellular reduction. Biotechnology annual review 11: 127.152-

16. Bruix, J. \& Sherman, M. (2011). Management of hepatocellular carcinoma: an update. Hepatology 53(3): 10201022.

17. Bun, S., Bun, H., Guédon, D., Rosier, C. \& Ollivier, E. (2006). Effect of green tea extracts on liver functions in Wistar rats. Food and Chemical Toxicology 44(7): 1108-1113.

18. Chasapis, C. T., Loutsidou, A. C., Spiliopoulou, C. A. \& Stefanidou, M. E. (2012). Zinc and human health: an update. Archives of toxicology 86(4): 521-534.
19. Chhillar, R. \& Dhingra, D. (2013). Antidepressant-like activity of gallic acid in mice subjected to unpredictable chronic mild stress. Fundamental \& clinical pharmacology 27(4): 409-418

20. Claimer, C., Mahesh, A., Sinilal, B., Rao, D. \& Thangadurai, D. (2012). Protective effect of Indigofera aspalathoides roots on $\mathrm{N}$-nitrosodiethylamine-induced hepatocarcinogenesis in mice. Indian journal of pharmaceutical sciences 74(2): 157.

21. Daniel, M.-C. \& Astruc, D. (2004). Gold nanoparticles: assembly, supramolecular chemistry, quantum-size-related properties, and applications toward biology, catalysis, and nanotechnology. Chemical reviews 104(1): 293-346.

22. Darwish, H. A. \& EL-boghdady, N. A. (2013). Possible involvement of oxidative stress in diethylnitrosamine-induced hepatocarcinogenesis: chemopreventive effect of curcumin. Journal of Food Biochemistry 37(3): 353-361.

23. Doumas, WA, W. \& HG, B. (1971). : Albumin and the measurement of serum albumin with bromcresolgreen. Clin Chim Acta 31:87-96.

24. Ferlay, J., Soerjomataram, I., Dikshit, R., Eser, S., Mathers, C., Rebelo, M., Parkin, D. M., Forman, D. \& Bray, F. (2015) Cancer incidence and mortality worldwide: sources, methods and major patterns in GLOBOCAN 2012. International journal of cancer 136(5): E359-E386.

25. Franklin, R. B., Levy, B. A., Zou, J., Hanna, N., Desouki, M M., Bagasra, O., Johnson, L. A. \& Costello, L. C. (2012). ZIP14 zinc transporter downregulation and zinc depletion in the development and progression of hepatocellular cancer. Journal of gastrointestinal cancer 43(2): 249-257.

26. Giodini, L., Re, F. L ,.Campagnol, D., Marangon, E., Posocco, B., Dreussi, E. \& Toffoli, G. (2017). Nanocarriers in cancer clinical practice: a pharmacokinetic issue. Nanomedicine: Nanotechnology, Biology and Medicine 13(2): 583-599.

27. Goel, A., Dani, V. \& Dhawan, D. (2005). Protective effects of zinc on lipid peroxidation, antioxidant enzymes and hepatic histoarchitecture in chlorpyrifos-induced toxicity. Chemicobiological interactions 156(2-3): 131-140.

28. Harper, H. (1961). The functions and tests of the liver. Review of physiological chemistry. Los Altos, California: Lange Medical Publishers: 271-283.

29. Hatano, T., Edamatsu, R., HIRAMATSU, M., MORI, A., FUJITA, Y., YASUHARA, T., YOSHIDA, T. \& OKUDA, T. (1989). Effects of the interaction of tannins with co-existing substances. VI.: effects of tannins and related polyphenols on superoxide anion radical, and on 1, 1-Diphenyl-2picrylhydrazyl radical. Chemical and Pharmaceutical Bulletin 37(8): 2016-2021.

30. Henry, R. J. (1964). Colorimetric determination of tota protein. Clinical Chemistry. Harperand Row Publ., New York, USA, Pp. 181.

31. Jadon, A., Bhadauria, M. \& Shukla, S. (2007). Protective effect of Terminalia belerica Roxb. and gallic acid against carbon tetrachloride induced damage in albino rats. Journal of ethnopharmacology 109.218-214:

32. Jagan, S., Ramakrishnan, G., Anandakumar, P., Kamaraj, S. \& Devaki, T. (2008). Antiproliferative potential of gallic acid against diethylnitrosamine-induced rat hepatocellular carcinoma. Molecular and cellular biochemistry 319(1-2): 51.

33. Jendrassik, L. \& Grof, P. (1938). Colorimetric Method of Determination of bilirubin. Biochem Z 297: 81-82.

34. Kodydková, J., Vávrová, L., Kocík, M. \& Zak, A. (2014). Human catalase, its polymorphisms, regulation and changes of its activity in different diseases .Folia biologica 60(4): 153.

35. Lee, S. R. (2018). Critical role of zinc as either an antioxidant or a prooxidant in cellular systems. Oxidative medicine and cellular longevity 2018

36. Lemire, J., Mailloux, R. \& Appanna, V. D. (2008). Zinc toxicity alters mitochondrial metabolism and leads to decreased ATP production in hepatocytes. Journal of Applied Toxicology: An International Journal 28(2): 175-182.

37. Marino, T., Galano, A. \& Russo, N. (2014). Radical scavenging ability of gallic acid toward $\mathrm{OH}$ and $\mathrm{OOH}$ radicals. 
Reaction mechanism and rate constants from the density functional theory. The Journal of Physical Chemistry B 118(35): 10380-10389.

38. Moreno-Álvarez, S., Martínez-Castañón, G., Niño-Martínez, N., Reyes-Macías, J., Patiño-Marín, N., Loyola-Rodríguez, J \&Ruiz, F. (2010). Preparation and bactericide activity of gallic acid stabilized gold nanoparticles. Journal of Nanoparticle Research 12(8): 2741-2746.

39. Murray, R. L. ( 1984). Creatinine. . Clin Chem The CV Mosby Co. St Louis. Toronto. Princeton: 1261-126.6

40. Pashmforoosh, M., Rezaie, A., Haghi-Karamallah, M., Fazlara, A., Shahriari, A. \& Najafzadeh, H. (2015). Effects of caffeine on renal toxicity induced by diethylnitrosamine. Zahedan Journal of Research in Medical Sciences 17(1): 7-9.

41. Powell, S. R. (2000 .(The antioxidant properties of zinc. The Journal of nutrition 130(5): 1447S-1454S.

42. Prasad, A. S. (2009). Impact of the discovery of human zinc deficiency on health. Journal of the American College of Nutrition 28(3): 257-265.

43. Rajkapoor, B., Jayakar, B ,.Murugesh, N. \& Sakthisekaran, D. (2006). Chemoprevention and cytotoxic effect of Bauhinia variegata against $\mathrm{N}$-nitrosodiethylamine induced liver tumors and human cancer cell lines. Journal of ethnopharmacology 104(3): 407-409.

44. Ramakrishnan, G., Augustine, T. A., Jagan, S., Vinodhkumar, R. \& Devaki, T. (2007). Effect of silymarin on Nnitrosodiethylamine induced hepatocarcinogenesis in rats. Experimental oncology.

45. Rezaie, A., Fazlara, A., Karamolah, M. H., Shahriari, A., Zadeh, H. N. \& Pashmforosh, M. 2013 .Effects of Echinacea purpurea on hepatic and renal toxicity induced by diethylnitrosamine in rats. Jundishapur journal of natural pharmaceutical products 8(2): 60

46. Ružić, M., Pellicano, R., Fabri, M., Luzza, F., Boccuto, L., Brkić, S. \& Abenavoli, L .(2018) .Hepatitis C virus-induced hepatocellular carcinoma: a narrative review. Panminerva medica 60(4): 185-191.

47. Shaheen, N. (2014). Oxidative stress of diethylnitrosamine on the functions of kidney in male rats and effective role of rutin and/or selenium. Journal of Applied Sciences Research.

48. Shahin, Y., Elguindy, N., Abdel Bary, A. \& Balbaa, M. (2018). The protective mechanism of Nigella sativa against diethylnitrosamine-induced hepatocellular carcinoma through its antioxidant effect and EGFR/ERK1/2 signaling. Environmental toxicology 33(8): 885-898.

49. Sivaramakrishnan, V., Shilpa, P. N. M., Kumar, V. R. P. \& Devaraj, S. N. (2008). Attenuation of N-nitrosodiethylamine- induced hepatocellular carcinogenesis by a novel flavonolMorin. Chemico-biological interactions 171(1): 79-88.

50. Son, S. \& Lewis, B. A. (2002). Free radical scavenging and antioxidative activity of caffeic acid amide and ester analogues: Structure- activity relationship. Journal of agricultural and food chemistry 50(3): 468-472.

51. Stadtman, E \& .Levine, R. (2003). Free radical-mediated oxidation of free amino acids and amino acid residues in proteins. Amino acids 25(3-4): 207-218.

52. Swelam, E. S., Abdallah, I. S. \& Mossa, A.-T. H. (2017) Ameliorating effect of zinc against oxidative stress and lipid peroxidation induced by fipronil in male rats. J. Pharma Toxicol 121: 24-32.

53. Swift, M. L.,1997: GraphPad prism, data analysis, and scientific graphing. Journal of chemical information and computer sciences 37(2): 411-412.

54. Takeda, T.-a., Miyazaki, S., Kobayashi, M., Nishino, K., Goto, T., Matsunaga, M., Ooi, M., Shirakawa, H., Tani, F. \& Kawamura, T. (2018). Zinc deficiency causes delayed ATP clearance and adenosine generation in rats and cell culture models. Communications biology 1(1): 113

55. Truong-Tran, A., Ho, L., Chai, F. \& Zalewski, P. (2000). Cellular zinc fluxes and the regulation of apoptosis/genedirected cell death. The Journal of nutrition 130(5): 1459S$1466 \mathrm{~S}$.

56. Tupe, R. S., Tupe, S. G., Tarwadi, K. V. \& Agte, V. V. (2010). Effect of different dietary zinc levels on hepatic antioxidant and micronutrients indices under oxidative stress conditions. Metabolism 59(11): 1603-1611.

57. Turner, R. (2013). Screening methods in pharmacology. Elsevier

58. Whitby, L., Percy-Robb, I. \& Smith, A. (1984). Enzyme tests in diagnosis. Lecture notes in clinical chemistry. Blackwell Berlin 3: 138.

59. Yadav, A. S. \& Bhatnagar, D. (2007). Chemo-preventive effect of Star anise in N-nitrosodiethylamine initiated and phenobarbital promoted hepato-carcinogenesis. Chemicobiological interactions 169(3): 207-214.

60. Yapali, S. \& Tosun, N. (2018). Epidemiology and viral risk factors for hepatocellular carcinoma in the Eastern Mediterranean countries. Hepatoma Res 4: 24-34.

61. Yoshioka, H., Usuda, H., Nonogaki, T. \& Onosaka, S. (2016 . Carbon tetrachloride-induced lethality in mouse is prevented by multiple pretreatment with zinc sulfate. The Journal of toxicological sciences 41(1): 55-63 